EXTENDED REPORT

\title{
Pain and joint mobility explain individual subdimensions of the health assessment questionnaire (HAQ) disability index in patients with rheumatoid arthritis
}

\author{
A Häkkinen, H Kautiainen, P Hannonen, J Ylinen, M Arkela-Kautiainen, T Sokka
}

Ann Rheum Dis 2005;64:59-63. doi: 10.1136/ard.2003.019935

See end of article for authors' affiliations afficions

Correspondence to: $\operatorname{Dr}$ A Häkkinen, Department of 'Physical Medicine and Rehabilitation, Jyväskylä Central Hospital, 40620 Jyväskylä, Finland: arja.hakkinen@kssh.fi

Accepted 19 April 2004

Published Online First 6 May 2004

\begin{abstract}
Objective: To explore the associations between individual subdimensions of the health assessment questionnaire (HAQ) and clinical variables in patients with rheumatoid arthritis.

Methods: 304 patients with rheumatoid arthritis (73\% female, mean (SD) age, 58 (13) years; disease duration 6 (9) years, 69\% rheumatoid factor positive) completed the HAQ for functional capacity (0-3) and a $100 \mathrm{~mm}$ visual analogue scale for pain. Grip strength, range of motion of the large joints, Larsen score for radiographic damage of hand and foot joints, and the number of tender and swollen joints were recorded. A logit regression model was used to study associations between subdimensions of the HAQ and other variables.

Results: Mean (range) total HAQ score was $0.92(0$ to 2.88 ) and varied from 0.73 to 1.04 in the subdimensions. Disability was lowest in the "walking" and highest in the "reach" subdimension. Pain was an explanatory variable in all individual subdimensions. Decreased grip strength, limitation of shoulder and wrist motion, and a larger number of swollen and tender joints in the upper extremities were related to several subdimensions. A higher pain score and swollen joint count in the upper extremities, decreased grip strength, and limited motion of wrist, shoulder, and knee joints explained increased disability (higher total HAQ scores).

Conclusions: In patients with rheumatoid arthritis, pain and range of movements of joints have the greatest impact on individual subdimensions of the HAQ. Extent of radiographic damage in peripheral joints and the number of swollen and tender joints are of lesser importance for function.
\end{abstract}

$\mathrm{T}$ he negative consequences of rheumatoid arthritis on the physical function of patients are multidimensional, involving decrease in muscle strength and endurance and restricted range of movement (ROM) of joints. ${ }^{1}$ Consequently, a comprehensive assessment of a patient's physical function should be multifaceted and include specific tasks evaluated in a standardised manner using predetermined criteria, such as time, number of repetitions, force, and degrees of movement. ${ }^{2}$ Nevertheless, although measures of physical function provide objective information about the functional status of individual joints, they are rarely used as part of routine clinical monitoring, as this kind of assessment is time consuming. Further, they require trained monitors and special equipment.

Over the past two decades, assessment of patient health status has undergone a shift from a predominant reliance on biochemical, radiological, and physical performance measures to patients' self reported health status. ${ }^{3}$ The most widely used self report questionnaires in rheumatology are the health assessment questionnaire (HAQ), ${ }^{4}$ and its modified version MHAQ, ${ }^{5}$ developed to assess patients' functional capacity in daily activities.

Several studies show that the total HAQ score reflects disease activity and is associated with pain, swollen and tender joint counts, and laboratory tests that reflect inflammatory activity. ${ }^{6-8}$ To a lesser extent, the HAQ is also associated with radiographic damage to joints. ${ }^{67910}$ Furthermore, the total HAQ score is strongly correlated with the Keitel function test. ${ }^{11}$

Associations of clinical variables with patients' self reported function have usually been published as correlations with the total HAQ score, and little is known about the influence of impairment in individual joints on subdimensions of the HAQ. Thus our aim in the present study was to explore the extent to which limited motion of individual joints, the number of swollen and tender joints, grip strength, pain, and peripheral radiographic joint damage are associated with the eight subdimensions of the HAQ in patients with rheumatoid arthritis.

\section{METHODS}

Jyväskylä Central Hospital is the only rheumatology centre in the district of Central Finland (population 265 000). In all, 823 adult patients with rheumatoid arthritis were treated in the rheumatology inpatient ward from January 1996 to June 2000. Of these, $304(37 \%)$ were referred to a physiotherapist and are the participants in this study (table 1). All patients were treated actively with disease modifying antirheumatic drugs (DMARDs) from the time of diagnosis, according to a strategy that was in clinical use the time (the most frequently used DMARDs were sulfasalazine, methotrexate, and a combination of two or more DMARDs).

Functional status in activities of daily living was assessed by the Finnish version of the HAQ, ${ }^{11}$ which included 20 questions in eight subdimensions: dressing and grooming, arising, eating, walking, hygiene, reach, grip, and common daily activities. The response alternatives were 0 , able without any difficulty; 1 , able with some difficulty; 2 , able with much difficulty; and 3, unable. The highest response within each

Abbreviations: DMARD, disease modifying antirheumatic drug; $H A Q$, health assessment questionnaire; ROM, range of movement 
Table 1 Demographic, clinical, and radiographic characteristics of 304 patients with rheumatoid arthritis

\begin{tabular}{|c|c|c|}
\hline Variable & Characteristic & Range \\
\hline \multicolumn{3}{|l|}{ Demographic } \\
\hline Female/male & $223 / 81$ & \\
\hline Age (y) (mean (SD)) & $58(13)$ & 21 to 83 \\
\hline $\mathrm{BMI}\left(\mathrm{kg} / \mathrm{m}^{2}\right)($ mean $(\mathrm{SD}))$ & $26(4)$ & 15 to 44 \\
\hline Rheumatoid factor present (\%) & $211(69 \%)$ & \\
\hline Disease duration (y) (mean (SD)) & $6(9)$ & 0 to 44 \\
\hline \multicolumn{3}{|l|}{ Measures of disease activity } \\
\hline ESR (mm/h) (median (IQR)) & $33(19,50)$ & 0 to 118 \\
\hline Swollen joint count (median (IQR)) & $7(3,11)$ & 0 to 29 \\
\hline Tender joint count (median (IQR)) & $8(3,14)$ & 0 to 46 \\
\hline Pain (VAS) (median (IQR)) & $50(29,60)$ & 0 to 100 \\
\hline \multicolumn{3}{|l|}{ Radiographic } \\
\hline Larsen score (0-120) (median (IQR)) & $4(0,17)$ & 0 to 116 \\
\hline
\end{tabular}

$B M I$, body mass index; ESR, erythrocyte sedimentation rate; $I Q R$, interquartile range; VAS, visual analogue scale; $y$, years.

subdimension was used as a score for that function. For the total HAQ score, the sum of the highest response in each subdimension was divided by 8 to form a score with the range 0 to 3 .

Radiographs of hands and feet were taken in posterioranterior projection and assessed according to the Larsen score of 0 to 5 for each joint, ${ }^{12}{ }^{13}$ with a total score of 0 to 60 for the hands, including the wrists and the first to fifth metacarpophalangeal joints, and a total score of 0 to 60 for the feet, including the first to fifth metatarsophalangeal joints and the interphalangeal joints of the big toes. All were read by one of us (TS) without knowledge of the identity of the patient at the time of reading.

Sixty six joints were evaluated for swelling and 68 for tenderness. Swollen or tender joint counts in the upper extremities (including the hands, wrists, elbows, and shoulders) and lower extremities (including the feet, ankles, knees and hips) were used separately in the analyses. Erythrocyte sedimentation rate (ESR) was also recorded to reflect clinical disease activity. Patients completed a $100 \mathrm{~mm}$ visual analogue scale for pain (0, no pain; 100, worst possible pain). ${ }^{14}$

Four experienced physical therapists measured the range of motion (ROM) of the following joints, using a manual goniometer to within a level of accuracy of $5^{\circ}$ in standardised positions (Zimmer Orthopaedic, catalogue No 337): shoulder joints (flexion and abduction); elbow, wrist, and knee joints (flexion and extension). In both elbow and knee joints, mobility towards extension was expressed in degrees of extension deficit. A Jamar standard dynamometer was used to measure isometric grip strength ${ }^{15}$ and the best result of three attempts was taken for the final analysis. Mobility and grip strength results are expressed as a mean of the right and left sides.

\section{Statistical methods}

Values are reported as mean (SD) or medians with interquartile range (IQR) or 95\% confidence intervals (CI). Internal consistency was estimated by calculating Cronbach's $\alpha$ coefficients with a $95 \%$ one sided confidence interval for the HAQ subdimensions.

To explore possible relations of the variables with the various subdimensions of the HAQ, each subdimension was analysed separately. A forward stepwise ordered logit regression analysis was run using all the variables in the model that are shown in table 4 . In each subdimension the explanatory variables were adjusted for those variables included in model (in other words, variables that are shown in the table). ${ }^{16}$ The multiple imputation method (Markov chain Monte Carlo) was used to fill in missing values for individual HAQ questions. The study was approved by the ethics committee of Jyväskylä Central Hospital.

\section{RESULTS}

The mean age of the respondents was 58 years (range 21 to 83 ) and $73 \%$ were female. Mean disease duration was six years (range 0 to 44 ), and 69\% were rheumatoid factor positive (table 1). The median (IQR) Larsen score was 4 (0 to 17), and $67 \%$ of the patients had erosions on their hand or foot radiographs (46\% in the hands and 59\% in the feet) (table 1). In all, $84 \%$ and $64 \%$ of the patients had swollen joints and $85 \%$ and $76 \%$ had tender joints in their upper and lower extremities, respectively.

The ROMs of the joints assessed and the grip strengths are shown in table 2. Mean (range) total HAQ was 0.92 (0 to 2.88). Table 3 shows measurement metric data in more detail. Forward stepwise ordered logit regression analysis showed that total HAQ was related to pain, swollen joints of the upper extremity, grip strength, dorsal flexion of the wrist, shoulder flexion, and knee flexion (table 4). Pain was an explanatory variable in all subdimensions of the HAQ, and knee flexion in all but the "dressing and grooming" and "grip" subdimensions. Shoulder flexion and wrist flexion and extension explained several subdimensions, as did swollen or tender joint counts in the upper extremities. The number of swollen and tender joints in the lower extremities explained only "walking" and "common daily activities" subdimensions. Age and female sex were related to disability only in the "arising" subdimension, and the Larsen score for

\begin{tabular}{|c|c|c|}
\hline Variable & Mean (SD) & Range \\
\hline \multicolumn{3}{|l|}{ Wrist† } \\
\hline Dorsal flexion ${ }^{\circ}$ & $58(18)$ & 0 to 85 \\
\hline Volar flexion & $59(17)$ & 0 to 85 \\
\hline \multicolumn{3}{|l|}{ Elbowt } \\
\hline Flexion & $147(8)$ & 35 to 155 \\
\hline Extension deficit ${ }^{\circ}$ & $15(13)$ & 0 to 55 \\
\hline \multirow{2}{*}{\multicolumn{3}{|c|}{$\begin{array}{l}\text { [No of patients with extension deficit: } 67(22 \%)] \\
\text { Shouldert }\end{array}$}} \\
\hline Shouldert & & \\
\hline Flexion ${ }^{\circ}$ & $171(22)$ & 60 to 180 \\
\hline Abduction ${ }^{\circ}$ & $168(30)$ & 35 to 180 \\
\hline \multicolumn{3}{|l|}{ Knee† } \\
\hline Flexion & $132(9)$ & 70 to 140 \\
\hline Extension deficit $^{\circ}$ & $6(4)$ & 0 to 30 \\
\hline \multicolumn{3}{|l|}{ [No of patients with extension deficit: $18(6 \%)]$} \\
\hline Grip strength† $(\mathrm{kg})$ & $22(11)$ & 2 to 64 \\
\hline
\end{tabular}


Table 3 Internal consistency of different subdimensions and total health assessment questionnaire (HAQ)

\begin{tabular}{lllll}
\hline Subdimension & Number of items & Mean (range) & $\boldsymbol{\alpha} \dagger$ & $\mathbf{9 5 \%} \mathbf{C l}$ \\
\hline 1. Dressing and grooming & 2 & $0.82(0$ to 3$)$ & 0.73 & 0.68 \\
2. Arising & 2 & $0.87(0$ to 3$)$ & 0.76 & 0.71 \\
3. Eating & 3 & $0.99(0$ to 3$)$ & 0.84 & 0.81 \\
4. Walking & 2 & $0.73(0$ to 3$)$ & 0.82 & 0.78 \\
5. Hygiene & 3 & $1.00(0$ to 3$)$ & 0.75 & 0.70 \\
6. Reach & 2 & $1.04(0$ to 3$)$ & 0.71 & 0.65 \\
7. Grip & 3 & $0.87(0$ to 3$)$ & 0.77 & 0.73 \\
8. Common daily activities & 3 & $1.03(0$ to 3$)$ & 0.81 & 0.78 \\
Total HAQ & 8 & $0.92(0$ to 2.88$)$ & 0.91 & 0.89 \\
\hline TCronbach's $\alpha$ with fone sided (lower limit) confidence interval. & &
\end{tabular}

the feet only in the "hygiene" subdimension. The Larsen score in hands, elbow flexion and extension, and knee extension were not explanatory for any of the eight subdimensions of the HAQ.

\section{DISCUSSION}

The self reported total HAQ assesses fine movements of the upper extremities, locomotor activities of the lower extremities, and activities involving both the upper and lower extremities and trunk. Each category contains at least two specific component questions. In the present study the consistency of the individual subdimensions of the HAQ was relatively good, indicating that the items included in each subdimension measure the function they represent. In 1982 Fries $^{17}$ reported a total HAQ of 0.80 in 331 rheumatoid patients from a community based population. The average age of the patients was 51 years and the mean duration of disease 12 years. Their highest reported disability of 1.2 was in the "reach" subdimension and is comparable to our result of 1.04. However, their lowest disability of 0.4 was in the "eating" subdimension; the corresponding figure in our data was 0.99. As the subdimensions contain items that assess the function of the upper and lower extremities as well as the trunk simultaneously, a more detailed examination of the items may also allow us to judge the importance of each subdimension. Each of the subdimensions was related to four to six individual explanatory variables, but in general the associations were not very strong.

Pain is a major symptom in rheumatoid arthritis and is the leading reason for patients seeking medical care. ${ }^{18}{ }^{19}$ In this study, all eight subdimensions of the HAQ were explained by pain, suggesting that the HAQ measures similar disability constructs to those assessed by the pain scale. Thus one can conclude that pain, although a personal and subjective experience that varies among individuals, makes an important contribution to the individual's physical function. Pain associates strongly with HAQ-assessed disability, both in the early stage $^{2021}$ and in patients with long standing disease. $^{322} 23$ Thus global arthritis status remains incomplete if pain assessment is not included. This result is in line with the finding of Stratford and co-workers. ${ }^{24}$ In patients with osteoarthritis of the hip or knee, the combination of the time, pain, and exertion domains of documented performance improved the correlation between the self report and performance related measures.

The flexibility of a joint is influenced not only by bony structures but also by muscles, tendons, ligaments, and the joint capsule. ${ }^{25}{ }^{26}$ In rheumatoid arthritis, damage in cartilage and bone structures, narrowing of joint space, increased intra-articular liquid volume, swelling of soft tissues around the joints, and possible subsequent subluxation are additional important factors contributing to decreased joint mobility. Studies evaluating the associations between joint mobility and HAQ in rheumatoid arthritis are rare. ${ }^{27}{ }^{28}$ The
Escola Paulista de Medicina scale evaluates ROM scores for 10 individual joints and reportedly has a moderate correlation $(r=0.55)$ with total HAQ in rheumatoid arthritis. ${ }^{29}$ However, as shown in the present study, alterations in the range of movements of individual joints have different implications for the various subdimensions of the HAQ. For example, wrist volar flexion was related to the "hygiene", "grip", and "common daily activities" subdimensions, in contrast to wrist dorsal flexion, which seemed to be crucial in the "dressing and grooming" subdimension. This indicates that the real range of movement in individual joints should be borne in mind when assessing physical function.

In earlier phases of rheumatoid arthritis, HAQ-assessed disability has been shown to be related mainly to pain, tenderness, and inflammatory synovitis. Over time the relative importance of these features may decline as anatomical damage accumulates with increasing disease duration. ${ }^{30}$ In the present study, the number of swollen or tender joints in the lower extremities was only weakly related to the "walking" and "common daily activities" subdimensions that require weight bearing joint function. In the upper extremities, the number of swollen and tender joints was weakly related to the HAQ subdimensions requiring reach or grip. Previous studies have shown important and progressive loss of grip strength in rheumatoid patients over time. ${ }^{11}{ }^{31}$ In this study, grip strength explained the subdimensions of "eating", "reach", "grip", and "common daily activities" as satisfactorily as the total HAQ. Significant correlations between grip strength and the self reported global HAQ function were also shown earlier. ${ }^{31}{ }^{32}$ Besides serving as a measure of hand function and as a reflection of a more generalised disability, grip strength has also been shown to predict work disability ${ }^{33}$ and mortality. ${ }^{31}{ }^{34}$

In contrast to common expectations, the Larsen score for the hand joints did not explain any subdimension of the HAQ, and the Larsen score for the foot joints explained the "walking" subdimension only. Furthermore, although radiographs provide optimal documentation of the extent of joint destruction, conflicting results of their correlation with functional capacity have been reported. ${ }^{6} 72230323536$ In fact, two clusters of measures are observed in rheumatoid arthritis: radiographs are correlated at high levels with the duration of disease, laboratory measures, and deformities, while they are correlated at lower levels with age, joint swelling, joint tenderness, functional status, and pain, which are more strongly correlated with one another. ${ }^{37}$

\section{Conclusions}

In patients with rheumatoid arthritis, pain and joint mobility impose a major impact on individual subdimensions of the HAQ, while the extent of radiographic damage in the peripheral joints and the numbers of swollen and tender joints appear to be of minor importance for these functions. 

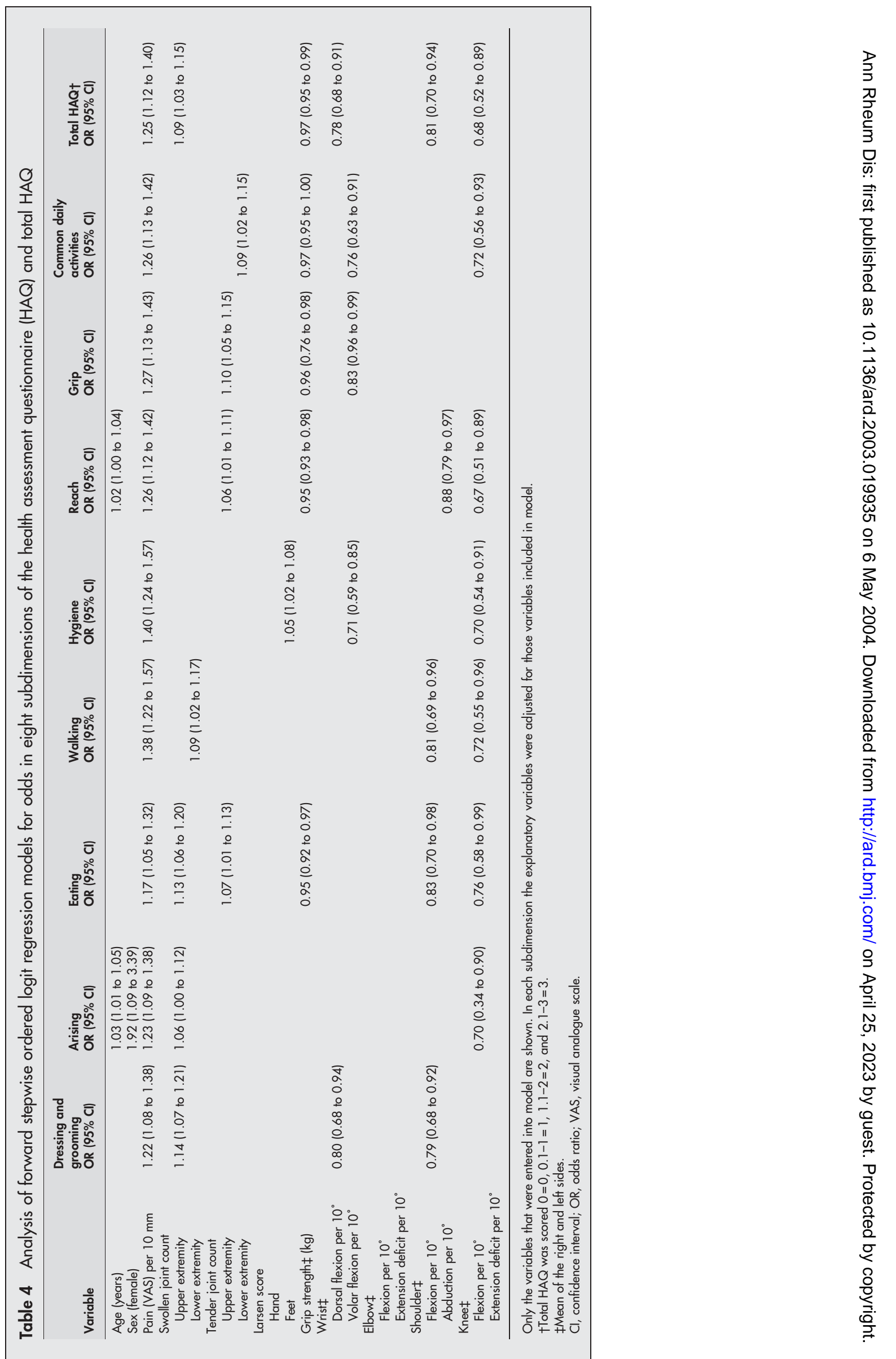


\section{Authors' affiliations}

A Häkkinen, J Ylinen, Department of Physical Medicine and

Rehabilitation, Jyväskylä Central Hospital, Finland

P Hannonen, T Sokka, Department of Medicine, Jyväskylä Central

Hospital

H Kautiainen, M Arkela-Kautiainen, Rheumatism Foundation Hospital,

Heinola, Finland

T Sokka, Vanderbilt University, Nashville, Tennessee, USA

\section{REFERENCES}

1 Stenström CH, Minor MA. Evidence for the benefit of aerobic and strengthening exercise in rheumatoid arthritis. Arthritis Rheum 2003;49:428-34

2 Strafford PW, Kennedy D, Pagura S, Gollish J. The relationship between selfreport and performance-related measures: questioning the content validity of timed tests. Arthritis Rheum 2003:49:535-40.

3 Bruce B, Fries JJ. The Stanford Health Assessment Questionnaire: a review of its history, issues, progress, and documentation. J Rheumatol 2003;30:167-78

4 Fries JF, Spitz P, Kraines RG, Holman HR. Measurement of patient outcome in arthritis. Arthritis Rheum 1980;23:137-45.

5 Pincus T, Summey JA, Soraci SA, Wallston KA, Hummon NP. Assessment of patient satisfaction in activities of daily living using a modified Stanford Health Assessment Questionnaire. Arthritis Rheum 1983;26:1346-53.

6 Pincus T, Callahan LF, Brooks RH, Fuchs HA, Olsen NJ, Kaye JJ. Self-report questionnaire scores in rheumatoid arthritis compared with traditional physical, radiographic, and laboratory measures. Ann Intern Med 1989; 110:259-66.

7 Sokka T, Kankainen A, Hannonen P. Scores for functional disability in patients with rheumatoid arthritis are correlated at higher levels with pain scores than with radiographic scores. Arthritis Rheum 2000;43:386-9.

8 Welsing PM, van Gestel AM, Swinkels HL, Kiemeney LA, van Riel PL. The relationship between disease activity, joint destruction, and functional capacity over the course of rheumatoid arthritis. Arthritis Rheum 2001;44:2009-17.

9 Guillemin F, Suurmeijer T, Krol B, Bombardier C, Briancon S, Doeglas D, et al. Functional disability in early rheumatoid arthritis: description and risk factors. J Rheumatol 1994;21:1051-5.

10 Drossaers-Bakker KW, Kroon HM, Zwinderman AH, Breedveld FC, Hazes JM Radiographic damage of large joints in long-term rheumatoid arthritis and its relation to function. Rheumatology (Oxford) 2000;39:998-1003.

11 Hakala M, Nieminen P, Koivisto O. More evidence from a community based series of better outcome in rheumatoid arthritis. Data on the effect of multidisciplinary care on the retention of functional ability. J Rheumatol 1994;21:1432-7.

12 Larsen A, Dale K, Eek M. Radiographic evaluation of rheumatoid arthritis and related conditions by standard reference films. Acta Radiol Diagn (Stockh) 1977; 18:481-91.

13 Larsen A. How to apply Larsen score in evaluating radiographs of rheumatoid arthritis in long-term studies. J Rheumatol 1995;22:1974-5.

14 Price D, McGrath P, Rafii A, Buckingham B. The validation of visual analogue scales as ratio scale measures for chronic and experimental pain. Pain 1983;17:45-56.

15 Mathiowetz V, Candidate PD. Reliability and validity of grip and pinch strength measurements. Phys Rehab Med 1991;4:201-12.

16 Stata Corporation. STATA base reference manual, vol 3. College Station. Texas: Stata Corporation, 2003.
17 Fries J. The dimensions of health outcomes: the Health Assessment Questionnaire disability and pain scales. J Rheumatol 1982;9:789-93.

18 Heiberg T, Kvien TK. Preferences for improved health examined in 1024 patients with rheumatoid arthritis: pain has highest priority. Arthritis Rheum 2002;47:391-7.

19 Sokka T. Assessment of pain in patients with rheumatic diseases. Best Pract Res Clin Rheumatol 2003;17:427-49.

20 Wolfe F, Hawley DJ, Cathey MA. Clinical and health status measures over time: prognosis and outcome assessment in rheumatoid arthritis. J Rheumatol 1991;18:1290-7.

21 Sarzi-Puttini P, Fiorini T, Panni B, Turiel M, Cazzola M, Atzeni F. Correlation of the score for subjective pain with physical disability, clinical and radiographic scores in recent onset rheumatoid arthritis. BMC Musculoskelet Disord 2002;3:18.

22 Molenaar ET, Voskuyl AE, Dijkmans BA. Functional disability in relation to radiological damage and disease activity in patients with rheumatoid arthritis in remission. J Rheumatol 2002;29:267-70.

23 Ward M, Leigh P. The relative importance of pain and functional disability to patients with rheumatoid arthritis. J Rheumatol 1993;20:1494-9.

24 Stratford PW, Kennedy D, Pagura SMC, Collish JD. The relationship between self-report and performance-related measures: questioning the content validity of timed tests. Arthritis Rheum 2003;49:535-40.

25 Corbin C. Flexibility. Clin Sports Med 1984;3:101-17.

26 Boström C. Shoulder rotational strength, movement, pain and joint tenderness as indicators of upper-extremity activity limitation in moderate rheumatoid arthritis. Scand J Rehab Med 2000;32:134-9.

27 Ferraz M, Oliviera L, Araujo P, Atra E, Walter S. EPM-ROM Scale: an evaluative instrument to be used in rheumatoid arthritis trials. Clin Exp Rheumatol 1990:8:491-4.

28 Badley E, Wagstaff S, Wood P. Measures of functional ability (disability) in arthritis in relation to impairment of range of joint movement. Ann Rheum Dis 1984;43:563-9.

29 Vliet Vlieland T, van den Ende C, Breedveld F, Hazes J. Evaluation of joint mobility in rheumatoid arthritis trials: the value of EPM-range of motion scale. J Rheumatol 1993;20:2010-14.

30 Scott DL, Pugner K, Kaarela K, Doyle DV, Woolf A, Holmes J, et al. The links between joint damage and disability in rheumatoid arthritis. Rheumatology (Oxford) 2000;39:1434-5.

31 Pincus T, Callahan LF. Rheumatology function tests: grip strength, walking time, button test and questionnaires document and predict longterm morbidity and mortality in rheumatoid arthritis. J Rheumatol 1992;19:1051-7.

32 Jäntti JK, Kaarela K, Luukkainen RK, Kautiainen HJ. Prediction of 20-year outcome at onset of seropositive rheumatoid arthritis. Clin Exp Rheumatol 2000;18:387-90

33 Callahan LF, Bloch DA, Pincus T. Identification of work disability in rheumatoid arthritis: physical, radiographic and laboratory variables do not add explanatory power to demographic and functional variables. J Clin Epidemiol 1992;45:127-38.

34 Pincus T, Callahan LF, Vaughn WK. Questionnaire, walking time and button test measures of functional capacity as predictive markers for mortality in rheumatoid arthritis. J Rheumatol 1987; 14:240-51.

35 Escalante A, del Rincon I. How much disability in rheumatoid arthritis is explained by rheumatoid arthritis? Arthritis Rheum 1999;42:1712-21.

36 Clarke AE, St-Pierre Y, Joseph L, Penrod J, Sibley JT, Haga M, et al. Radiographic damage in rheumatoid arthritis correlates with functiona disability but not direct medical costs. J Rheumatol 2001;28:2416-24

37 Pinus T, Sokka T. Quantitative measures for assessing rheumatoid arthritis in clinical trials. Best Pract Res Clin Rheumatol 2003;17:753-81. 